\title{
Using Pavlovian Higher-Order Conditioning Paradigms to Investigate the Neural Substrates of Emotional Learning and Memory
}

\author{
Jonathan C. Gewirtz ${ }^{1,3}$ and Michael Davis ${ }^{2}$ \\ ${ }^{1}$ University of Minnesota, Minneapolis, Minnesota 55455, USA; ${ }^{2}$ Emory University, Atlanta, Georgia 30322, USA
}

\begin{abstract}
In first-order Pavlovian conditioning, learning is acquired by pairing a conditioned stimulus (CS) with an intrinsically motivating unconditioned stimulus (US; e.g., food or shock). In higher-order Pavlovian conditioning (sensory preconditioning and second-order conditioning), the CS is paired with a stimulus that has motivational value that is acquired rather than intrinsic. This review describes some of the ways higher-order conditioning paradigms can be used to elucidate substrates of learning and memory, primarily focusing on fear conditioning. First-order conditioning, second-order conditioning, and sensory preconditioning allow for the controlled demonstration of three distinct forms of memory, the neural substrates of which can thus be analyzed. Higher-order conditioning phenomena allow one to distinguish more precisely between processes involved in transmission of sensory or motor information and processes involved in the plasticity underlying learning. Finally, higher-order conditioning paradigms may also allow one to distinguish between processes involved in behavioral expression of memory retrieval versus processes involved in memory retrieval itself.
\end{abstract}

By reducing learning to its most rudimentary components, the influence of undefined and uncontrollable confounding variables can be minimized. Consequently, much of the progress that has been achieved in searching for the neural substrates of learning and memory has been made using some of the simplest forms of learning. In one such paradigm, first-order Pavlovian conditioning, a conditioned stimulus (CS, such as a tone or light) acquires motivational significance by being paired with an intrinsically aversive or rewarding unconditioned stimulus (US, such as foot shock or food). Learning is evaluated by the ability of the CS to elicit a conditioned response (CR) in anticipation of the occurrence of the US. The use of first-order conditioning has revealed genetic and cellular mechanisms underlying learning and memory in species ranging from the fruit fly and sea snail to the mouse and rat.

Thus far, less attention has been paid by neurobiologists to the potential uses of higher-order Pavlovian conditioning, learning phenomena in which a CS (S2) acquires associative strength by being paired with another CS (S1) rather than with a US. The pairing of S2 with S1 may occur before $S 1$ is paired with the US (sensory preconditioning) or after S1 has been paired with the US (second-order conditioning; see Table 1). The cardinal feature of both sensory

${ }^{3}$ Corresponding author.

E-MAIL jgewirtz@umn.tc.edu; FAX (612) 626-2079.

Article and publication are at www.learnmem.org/cgi/doi/ $10.1101 / \mathrm{lm} .35200$. preconditioning and second-order conditioning-and that which recommends these paradigms to the service of neurobiologists interested in learning and memory-is that S2 acquires associative strength even though it is never paired directly with a US.

This article will describe two promising avenues of research in higher-order conditioning. First, the fact that reinforcing value is acquired makes higher-order conditioning well suited to investigating the neural substrates of different forms of reinforcement. Second, the absence of direct pairings between the CS and US allows one to characterize the roles played by molecular, genetic, pharmacological, and anatomical mechanisms in different stages of learning or memory more precisely than could be achieved using other conditioning paradigms.

\section{Higher-Order Conditioning: Fact or Artifact?}

There have been countless demonstrations of second-order conditioning since Pavlov (1927) first showed that salivation could be conditioned to a black square by pairing it with the sound of a metronome that had previously been paired with food. However, to demonstrate higher-order conditioning conclusively, two criteria should be met: the ability of S2 to elicit a conditioned response must result directly from the pairing of $S 2$ with $S 1$, and the ability of $S 1$ to support conditioning must result directly from its pairing (previous or subsequent) with the US (Rizley and Rescorla 1972). A large number of experiments conducted since the 1960 s that have included control groups appropriate to meet the first criterion (e.g., Kamil 1969; McAllister and

LEARNING \& MEMORY 7:257-266 @ 2000 by Cold Spring Harbor Laboratory Press ISSN1072-0502/00 \$5.00

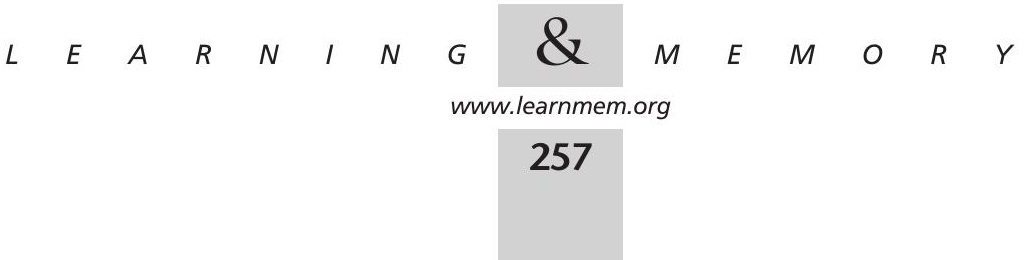


Table 1. Phases of Training in First-Order Conditioning, Second-Order Conditioning, and Sensory Preconditioning Paradigms

\begin{tabular}{lccc}
\hline Paradigm & $\begin{array}{c}\text { Phase 1 } \\
\text { training }\end{array}$ & $\begin{array}{l}\text { Phase 2 } \\
\text { training }\end{array}$ & Test \\
\hline First-order conditioning & S1-US & $\ldots$ & S1? \\
Second-order conditioning & S1-US & S2-S1 & S2? \\
Sensory preconditioning & S2-S1 & S1-US & S2? \\
\hline
\end{tabular}

McAllister 1964; Prewitt 1967; Tait et al. 1969) and several that have included control groups appropriate to meet the second (e.g., Pfautz et al. 1978; Rizley and Rescorla 1972) have still revealed evidence of robust second-order conditioning and sensory preconditioning. However, clear demonstrations of higher-order conditioning in some studies do not authenticate demonstrations of higher-order conditioning in other studies conducted under very different circumstances. Thus, it is important when using these procedures to include, at least initially, control groups where S2 and S1 are explicitly unpaired in time to rule out stimulus generalization (i.e., the tendency for a response to generalize from one stimulus to another), the most likely source of experimental artifact in higher-order conditioning paradigms.

Although second-order conditioning and sensory preconditioning are intrinsically weaker than first-order conditioning they can, at least, be enhanced by ensuring that first-order conditioning is particularly strong. This can be achieved by using a US of high value or intensity (Helmstetter and Fanselow 1989; Rescorla and Furrow 1977). With regard to second-order conditioning, "refresher" first-order conditioning trials can be interspersed during the phase of second-order conditioning. This prevents the extinction of first-order conditioning that would otherwise result from the presentation of $\mathrm{S} 1$ in the absence of reinforcement.

Other factors identified as being important in determining the strength of higher-order conditioning are the similarity of S1 and S2 and the temporal and physical distance between them. In cases where the conditioned stimuli are localized in space (e.g., differently colored key lights), second-order conditioning is enhanced when S2 and S1 are in close spatial proximity (Rescorla 1979; Rescorla and Cunningham 1979). Second-order conditioning also can be favored when S1 and S2 are stimuli within the same sensory modality (Rescorla and Furrow 1977; but see Holland 1977). Sensory preconditioning is most strongly acquired when S1 and S2 are presented simultaneously, although the superiority of this arrangement can only be detected using a sophisticated set of control procedures (Rescorla 1980b).

However, even with the above conditions in place, one difficulty with the use of second-order conditioning is that learning appears typically to be transient. That is, second- order conditioning usually reaches asymptote after a small number of trials and begins to decline with further training. The most plausible interpretation of this transience is that with greater training, second-order learning is obscured by the development of conditioned inhibition (e.g., Herendeen and Anderson 1968; Rescorla 1973; Holland and Rescorla 1975b; Yin et al. 1994). A conditioned inhibitor signals the nonoccurrence of reinforcement and, thus, inhibits the elicitation of conditioned responses by excitatory stimuli. It is not hard to see why procedures described above that produce second-order conditioning-S1 is reinforced on every occasion it is presented (S1-US trials) except when it is accompanied by S2 (S2-S1-no US trials)—would also produce conditioned inhibition. In fact, this training procedure (also called a feature-negative discrimination) is often the procedure of choice for generating conditioned inhibition. Hence, the transience of second-order conditioning can be explained if one assumes that second-order conditioning develops more rapidly than conditioned inhibition, the two effects are antagonistic at the level of the behavioral response, and conditioned inhibition is ultimately the stronger of the two phenomena so that it obscures second-order conditioning as the amount of training is increased (Fig. 1).

The interplay between second-order conditioning and conditioned inhibition thus creates an inverted U-shaped function, relating the strength of second-order conditioning to the number of training trials. Potentially, this can lead to interpretive problems. For example, a lesion, drug, or genetic manipulation that decreased second-order conditioning might do so by enhancing conditioned inhibition rather than actually impairing second-order conditioning. Paradoxically, therefore, a treatment that actually enhanced overall learning might appear to impair learning if one looked only at second-order conditioning. Thus, for second-

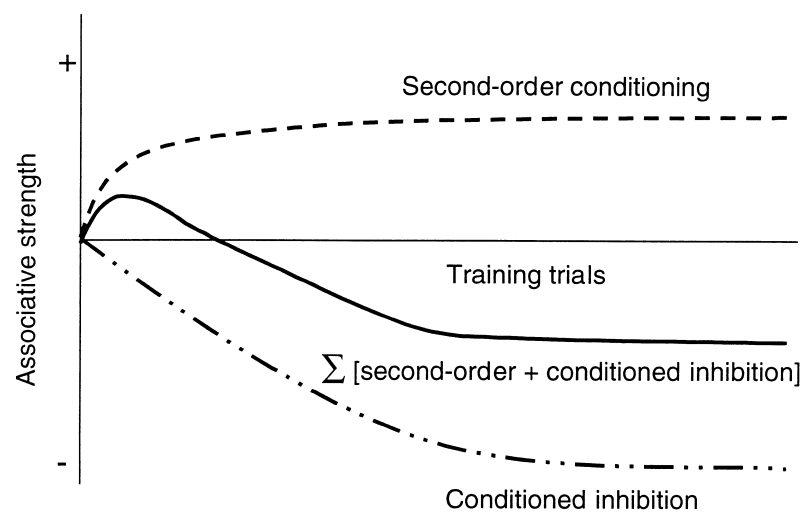

Figure 1 An explanation in schematic terms of the transience of second-order conditioning, frequently observed in the literature. In such cases, it is assumed that the size of the conditioned response is constrained by the sum of second-order conditioning and conditioned inhibition. It should be noted that negative conditioned responses are not observed in most paradigms.

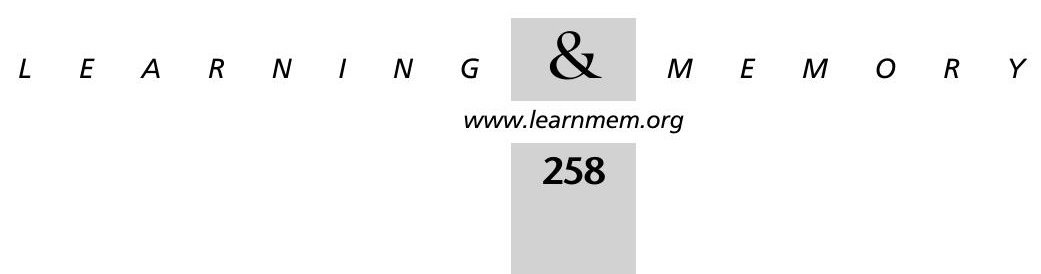


order conditioning to be useful, one has to control for the potential confound of conditioned inhibition.

One solution is to arrange training parameters that favor the development of second-order conditioning over conditioned inhibition. Pavlov's (1927) recommendation of using trace conditioning has not been proven to solve this problem (e.g., Kehoe et al. 1981). A more promising approach is the use of a partial reinforcement procedure during first-order conditioning (i.e., a mixture of S1+ and S1trials, rather than $\mathrm{S} 1+$ trials only). This clearly has a deleterious impact on conditioned inhibition (Rescorla 1999), while producing robust second-order conditioning (Kamil 1969; Gewirtz and Davis 1997a).

A second solution is to find a measure of second-order conditioning that is not affected by the presence of conditioned inhibition. Holland and Rescorla (1975b) observed both conditioned inhibition and second-order conditioning to the same CS in an appetitive conditioning paradigm relative to an unpaired control group. After substantial training, S2 still elicited conditioned responding itself (i.e., secondorder conditioning), but suppressed conditioned responding to S1 when the two stimuli were presented in compound (i.e., S2 also passed the summation test of conditioned inhibition.) We have made a similar observation in fear conditioning, using the fear-potentiated startle paradigm. In this paradigm, fear is measured as the enhancement in the amplitude of the startle reflex in the presence versus the absence of a CS. Thus, the time course of the fear response can be measured by presenting the startle-eliciting stimulus at different time points relative to the onset and offset of the CS (Davis et al. 1989). Using a serial S2-S1 training procedure, Falls and Davis (1997) found evidence of second-order fear-potentiated startle when the startle reflex was elicited in test during S2 but of conditioned inhibition of fear-potentiated startle when the reflex was elicited after the offset of S2. Therefore, using this procedure, second-order fear is not masked by conditioned inhibition, even after very extensive second-order training. In fact, rather than an inverted-U function, we found that secondorder conditioning increased monotonically as a function of the degree of second-order training (Fig. 2).

\section{Higher-Order Conditioning: Window on the Architecture of Memory}

Associative learning involves the development of associations between neural representations of events (e.g., Konorski 1967). Debate about the nature of these associations preoccupied traditional learning theorists perhaps more than any other issue. Much of the argument concerned whether the organism learned about the relationship between one stimulus and another (S-S learning), between a stimulus and a response (S-R learning), or between two responses (R-R learning). Some theorists attempted to ac-

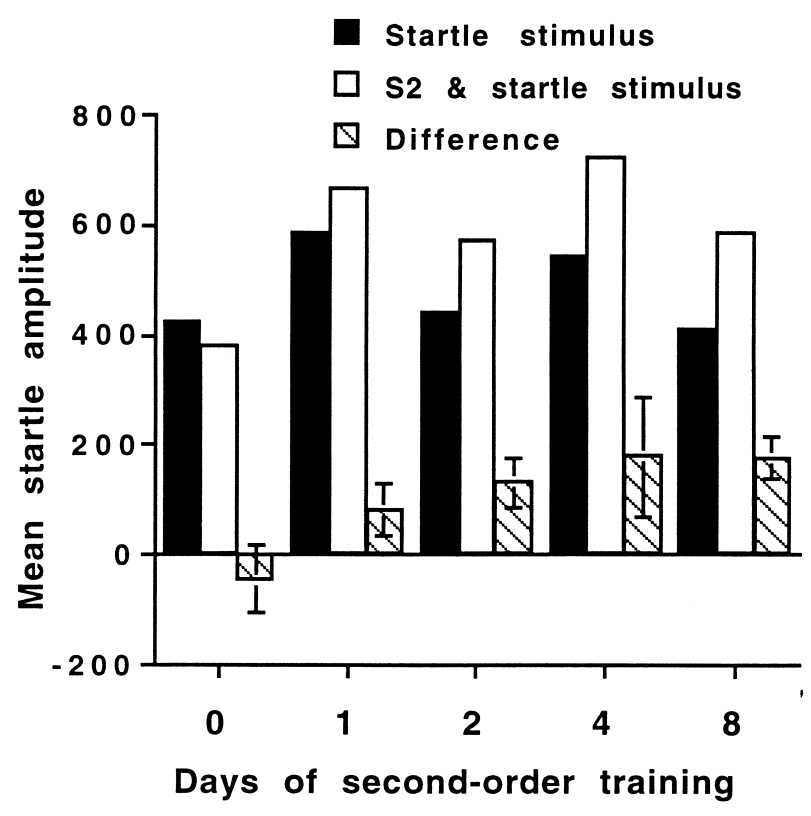

Figure 2 Second-order fear conditioning can still be observed after very extensive training when the fear-potentiated startle paradigm is used (Gewirtz 1998). There were 16 S2-S1 trials presented on each day of second-order training. Fear-potentiated startle is defined as the difference $( \pm$ SEM) in startle amplitude measured in the presence versus absence of the CS.

count for all learning through a single mechanism (e.g., Hull 1943), but it is now more generally appreciated that a conditioned stimulus can enter into an association with a variety of elements in a given learning situation (Rescorla 1980a; Rashotte 1981). As will be seen below, more than one form of association can be demonstrated in higherorder conditioning, depending on the arrangement of S2 and S1. Thus, higher-order conditioning offers a means of analyzing the structure of associations formed in learning, thereby providing an important base from which to elucidate biological mechanisms of associative learning.

As outlined by Rizley and Rescorla (1972), higher-order learning might be based primarily on associations between representations of S2 and S1 (S-S learning), representations of S2 and the US (S-US learning), or representations of S2 and the conditioned response elicited by the US (S-R learning; Fig. 3). In sensory preconditioning, the two conditioned stimuli are paired before the US is presented and, therefore, before the development of a strong conditioned response to $\mathrm{S} 1$. Hence, despite an appeal by some S-R theorists to the existence of covert and unmeasurable behavioral responses (Miller 1951), sensory preconditioning would seem to represent as clear a case as one could obtain of S-S learning.

However, it is less easy to predict the nature of the associations formed in second-order conditioning. These alternatives began to be evaluated in a systematic manner through a series of elegant experiments (Rizley and Res-

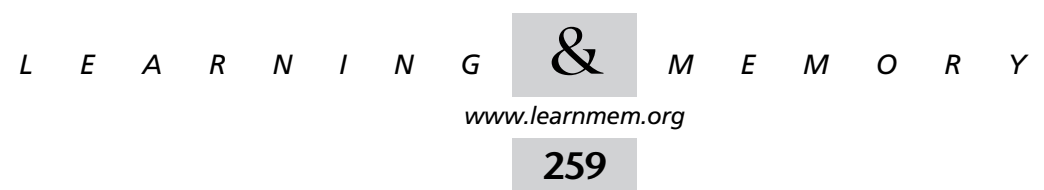




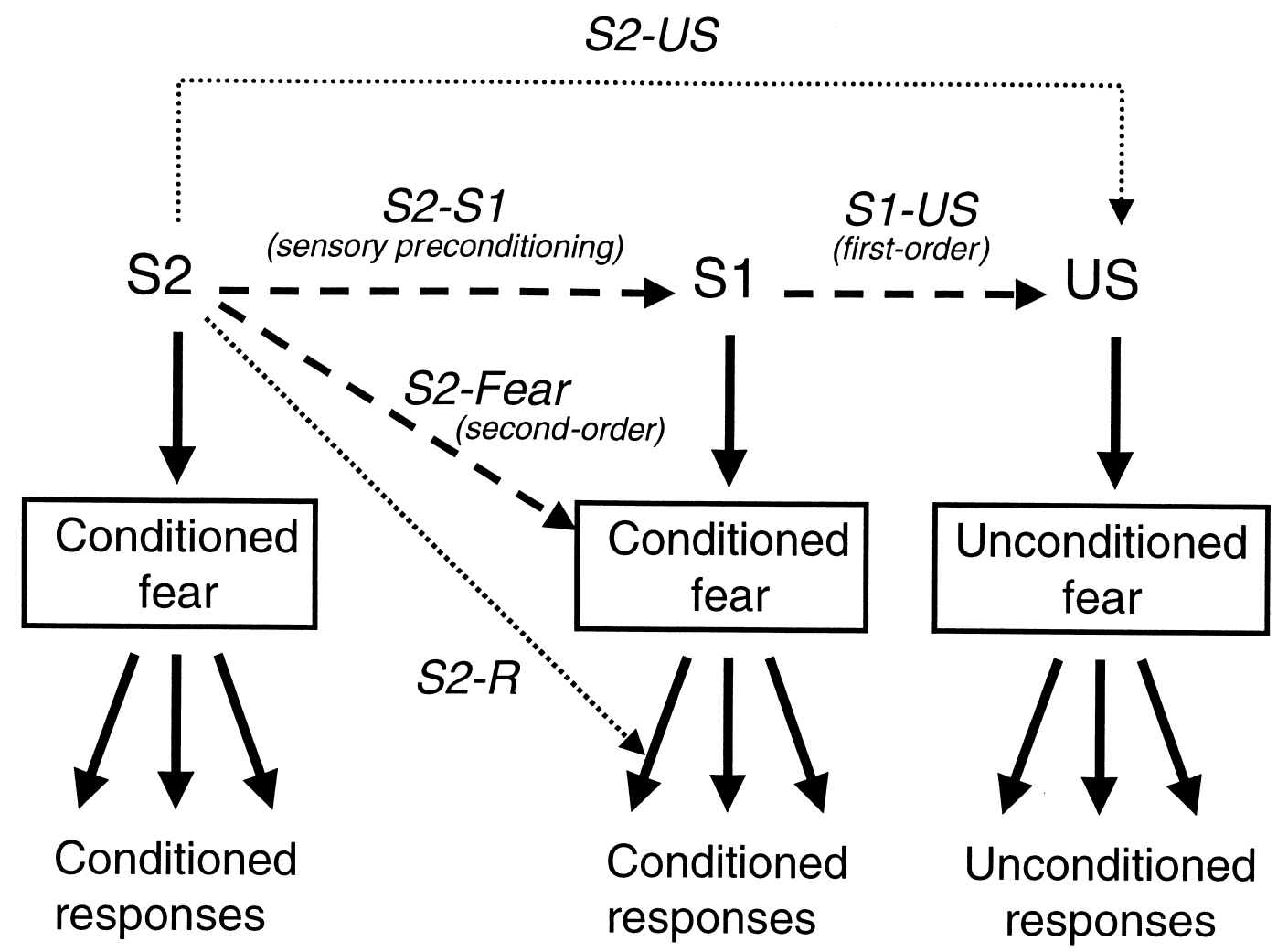

Figure 3 A schematic representation of hypothetical associations that could be formed in higher-order fear conditioning. Dashed arrows indicate probable representations activated during retrieval of first-order conditioning (S1-US), second-order conditioning (S2-Fear), and sensory preconditioning (S2-S1), based on the existing literature. Dotted arrows indicate other possible representations that may be activated during retrieval of second-order conditioning (see text for explanation).

corla 1972; see also Konorski 1948; Rozeboom 1958). The general approach was to assess the effects of various posttraining manipulations on the strength of second-order conditioning. For example, if the conditioned response to S1 were extinguished, what would be the effect on the response to S2? If S2 is associated with S1, then extinction of responding to $\mathrm{S} 1$ should also cause extinction of responding to S2. In fact, in sensory preconditioning, the prototypic measure of S-S learning, repeated nonreinforcement of S1 leads to extinction of responding to $\mathrm{S} 1$ as well as extinction of responding to S2 (e.g., Archer and Sjoden 1982; Rizley and Rescorla 1972). In contrast, most evidence suggests that when S2 and S1 are paired in a second-order conditioning procedure, nonreinforcement of $\mathrm{S} 1$ does not lead to extinction of responding to S2 (e.g., Rizley and Rescorla 1972). This suggests that S-S associations are not, in general, the basis of second-order conditioning.

How can one assess the possibility that second-order retrieval involves direct activation of a representation of the US (S2-US learning)? Interestingly, this appears to be the basis of retrieval of first-order associations, as the first-order conditioned response is sensitive to posttraining alterations in the value of the US. For example, a CS is paired with food so that a conditioned response can be measured. The US can then be devalued by pairing it with sickness. Following such treatment, animals show a reduction in the conditioned response to the CS compared to animals that did not experience US devaluation. This suggests that during conditioning, animals form a representation of the value of the US with which the CS has been paired. When that representation is changed (either devalued or inflated), then the behavior elicited by the cue also is changed in the same direction. However, second-order conditioning is generally not affected by these treatments, suggesting that an association between S2 and the US does not constitute the primary form of learning in second-order conditioning (e.g., Holland and Rescorla 1975a; Helmstetter and Fanselow 1989).

Further evidence that first- but not second-order conditioning involves the encoding of a detailed representation of the US was obtained in an elegant study that measured the topography of pigeons' keypecks in response to CSs that had been paired with food or water (Stanhope 1992). While pigeons pecked more forcefully for an S1 that had been paired with food than for an S1 that had been paired with water, the force of keypecks to S2 was not similarly

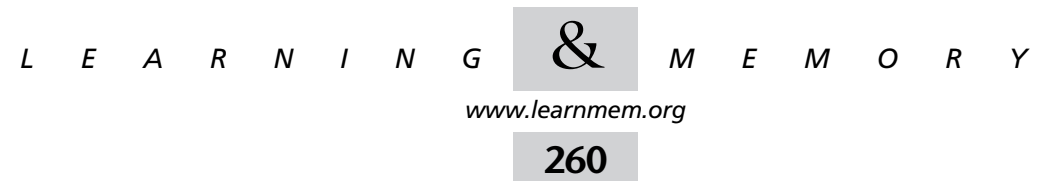


dependent on the nature of the reinforcer with which S1 previously had been paired.

On the basis of the devaluation and inflation data, Rescorla $(1973 ; 1980 a)$ reasoned that only an association between S2 and the conditioned response to S1 (S-R) learning would be immune to changes in the values of S1 and the US. However, this conclusion was arrived at by default and not on the basis of any direct evidence. In fact, other evidence suggests that S2 is not associated with an overt behavioral response. This is indicated by the finding that the specific form of the conditioned response produced by $\$ 2$ may be different from the conditioned response produced by S1, when the two stimuli are in different sensory modalities (Holland 1977; Kim et al. 1996). For example, whereas a light paired with food produces a rearing response, a tone paired with the light produces a quick, startle-like response but little evidence of rearing (Holland 1977).

Evidence of second-order fear-potentiated startle (see above) provides further demonstration of this point. The behavior used to measure fear (the startle reflex) is not a CR evoked by S1 ( $\mathrm{S} 1$ does not elicit startle but instead increases the amplitude of the startle reflex elicited by some other stimulus), and the startle reflex is not elicited at all during second-order training. Thus, the very existence of secondorder fear-potentiated startle demonstrates that second-order conditioning must involve more than simply an association between $\mathrm{S} 2$ and one or more overt behavioral responses produced by $\mathrm{S} 1$.

Therefore, although still often referred to in this way, S-R learning does not really provide an adequate description of second-order conditioning because $\mathrm{S} 2$ is not associated with a specific overt behavior. The interpretation most consistent with the data set as a whole is that S2 is associated with a central motivational state (Holland 1977). Thus, in the case of aversive learning, S2 anticipates a state of fear, rather than either a representation of the specific US with which S1 was paired or a specific CR elicited by S1. In the case of appetitive conditioning, S2 anticipates the delivery of reward, activating the hedonic system (Robinson and Berridge 1993) and producing, for wont of a better term, a state of hope (Mowrer 1960).

It should be noted that the general expectation of reward or punishment does not underlie second-order conditioning under all circumstances. For example, there have been isolated reports suggesting the presence of S2-US associations in second-order conditioning (Ross 1986; Barnet and Miller 1996). In addition, in one conditioning situation-autoshaping in pigeons-extinction of S1 substantially reduces the conditioned response to S2, suggesting that S2-S1 associations are the principle basis of secondorder conditioning in this paradigm (Leyland 1977; Rashotte et al. 1977). This does not reflect simply an idiosyncratic difference between pigeons and other species because rodents may also acquire S2-S1 second-order conditioning when two conditions are applied that normally promote strong sensory preconditioning: when S2 and S1 are presented simultaneously (as opposed to serially) and when very few first-order (S1-US) training trials are included (Rescorla 1982). These conditions minimize the incidence of $S 2$ in the absence of $\mathrm{S} 1$ and the incidence of S1 in the absence of S2. Because the stimuli are not experienced independent of one another, these arrangements may thus encourage S2-S1 learning through the formation of a unitary representation of the two stimuli (Rescorla and Durlach 1981).

In sum, sensory preconditioning involves the association between representations of S2 and S1. In contrast, in second-order conditioning, S2 comes to evoke a general expectation of reward or punishment, although S2-S1 learning can be encouraged under specific conditions. In this respect, it is interesting to note the asymmetry between second-order conditioning and first-order conditioning, in which S1 appears to evoke a memory of specific characteristics of the US. This means that one can use sensory preconditioning, second-order conditioning, and first-order conditioning to compare the neural substrates of S2-US, S2S1, and S2-Fear or S2-Hope learning.

The form of association that predominates in secondorder conditioning may also help in understanding the etiology of certain psychiatric disorders. For example, secondorder conditioning may provide a suitable nonhuman model for panic disorder, in which symptoms of agoraphobia develop as aversions to places in which panic attacks have occurred. That is, specific contextual cues may become associated with the fear of having a panic attack rather than with whatever triggered the attack in the first place.

\section{Higher-Order Conditioning and the Biology of Associative Learning and Memory}

\section{Mechanisms of Reinforcement I: Fear Conditioning}

The foregoing discussion suggests that comparisons of firstorder conditioning, sensory preconditioning, and secondorder conditioning might help us elucidate the neural substrates of three distinct forms of associative learning. The problem, however, in translating a model of associations based on behavioral data into a biological model is in reformulating the abstract concepts of S-S, S-US, and S-Fear or S-Hope learning into neural terms. We have suggested that these terms be defined with reference to the point or points of convergence in the brain of pathways conveying CS and US information (Gewirtz and Davis 1997b). Based on this idea, we have developed a schematic model of the pathways that may be involved in first- and higher-order fear conditioning (Fig. 4). This model assumes that pathways conveying S2, S1, and US information converge on one structure, the amygdala, that constitutes a site of plasticity of first-order conditioning. The second-order association is defined as S2-S1 if the S2 pathway inserts into the pathway

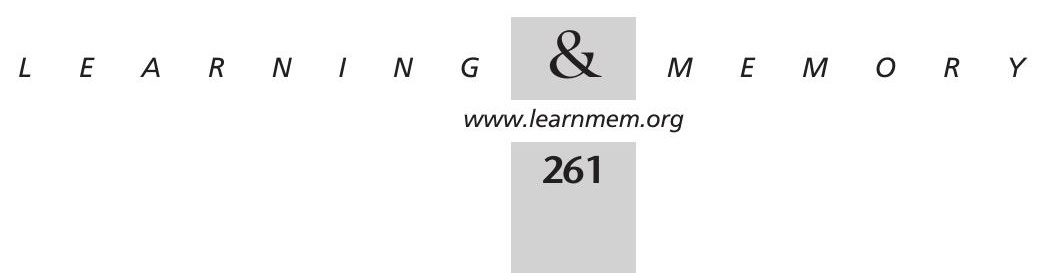




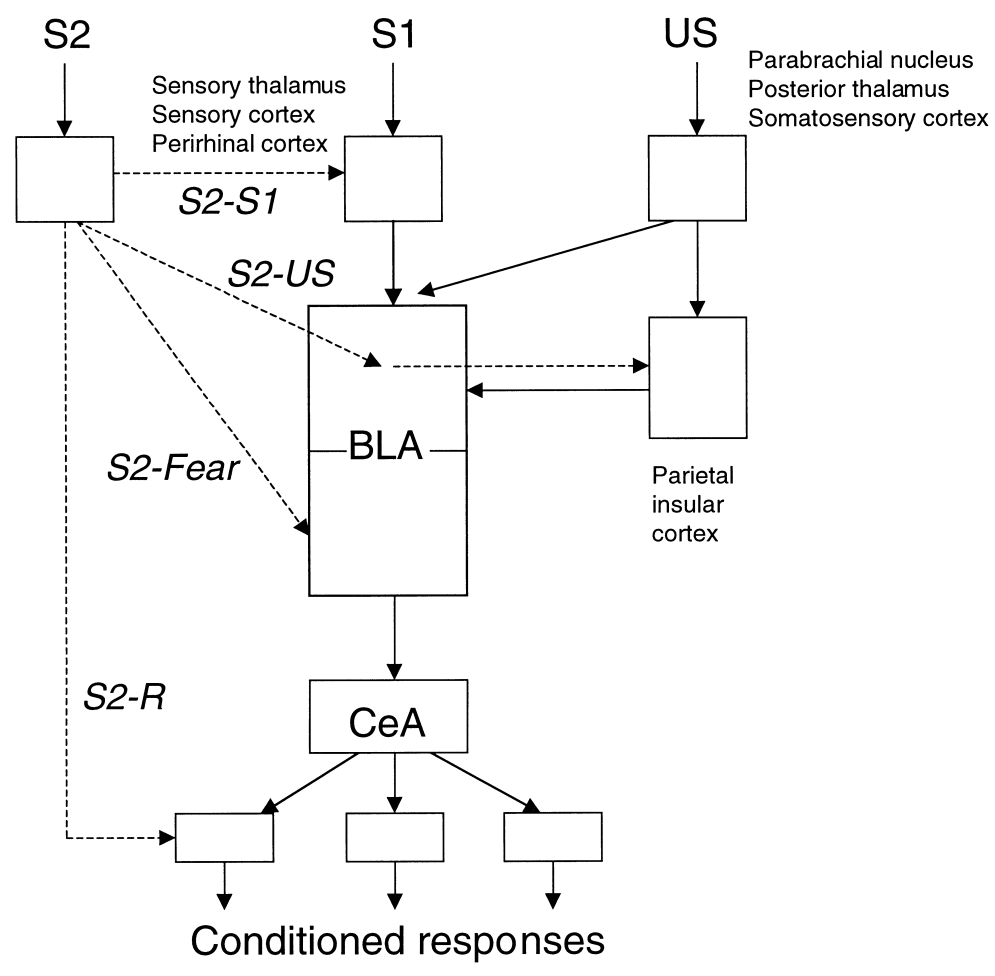

Figure 4 A highly simplified, schematic representation of a circuit for first- and higher-order fear conditioning (see text for explanation).

mediating first-order conditioning before the point of convergence between $\mathrm{S} 1$ and US information. It is defined as S2-US if it inserts into the first-order pathway at the point of S1-US convergence; as S2-Fear if it inserts after the point of S1-US convergence but before the point of divergence to different response systems; and as S2-R if it inserts after the point of response system divergence.

We assumed that S1-US convergence required for the acquisition of first-order fear conditioning occurs in the basolateral complex of the amygdala (BLA), probably in the lateral nucleus of the amygdala. This assumption is based on a variety of findings such as that CS and US sensory inputs converge onto the same cells of the lateral nucleus (Romanski et al. 1993) and that lesions (Campeau and Davis 1995b) and local infusion of $\mathrm{N}$-methyl-D-aspartate (NMDA) and nonNMDA-type glutamate receptor antagonists (Miserendino et al. 1990; Campeau et al. 1992; Kim et al. 1993; Lee and Kim 1998) into the BLA block first-order fear conditioning.

On the basis of the devaluation and inflation data, the model assumes that expression of first-order conditioning involves retrieval of a specific memory of the US (i.e., activation of a representation of the US). We postulated that this representation is stored outside the amygdala, in the form of a particular pattern of activity in regions of neocortex activated by the US itself. Retrieval of the memory for the US involves the production of a similar pattern of activation in these structures, initiated by the CS via the amygdala. Although lacking direct support, there are some data consistent with this view of retrieval of first-order fearful memories. Lesions made after training of posterior portions of insular cortex, particularly below the rhinal sulcus (formerly defined as part of perirhinal cortex; Rosen et al. 1992), block expression of first-order conditioning (Rosen et al. 1992; Campeau and Davis 1995a; Corodimas and LeDoux 1995; Falls et al. 1997). In contrast, acquisition is not blocked when lesions are made before training (Romanski and LeDoux 1992). Interestingly, the critical locus affected by these lesions contains sparse projections from visual and auditory areas but substantial projections from somatosensory cortex. Hence, it is unlikely that this region is required for transmission of CS information (auditory or visual) to the amygdala (Rosen et al. 1992; Campeau and Davis 1995a) or for retrieval of contextual information (Corodimas and LeDoux 1995) as has been suggested. Rather, this region may be part of a network of cortical structures that, orchestrated by the BLA, stores a representation of a somatosensory US. According to this view, when lesions are made after training, the US representation is degraded to the point where expression of conditioned fear is blocked; whereas, when lesions are made before training, a US representation can be acquired adequately using other cortical areas. Thus, the anatomical evidence and behavioral data are consistent with the view that lesions disrupt storage and retrieval of the US representation (Gewirtz and Davis 1997b; Shi 1995). Like first-order conditioning, second-order fear conditioning is dependent on NMDA-type glutamate receptor activation in the BLA (Gewirtz and Davis 1997a). Assuming, then, that second-order conditioning is similar to NMDA-dependent associative LTP, S2 would represent the weak stimulus and S1 the strong, depolarizing stimulus. If so, then one can ask where in this circuitry would S1 produce strong depolarization that would lead to S-Fear learning? Presumably this would be somewhere downstream of the site of first-order (i.e., S-US) plasticity. For example, within the BLA the lateral nucleus may be the site of first-order plasticity and the basal nucleus the site of second-order plasticity. The latter structure receives heavy projections from both the lateral nucleus (Pitkänen et al. 1995) and from perirhinal cortex (Shi 1995), both of which would be activated by $\mathrm{S} 1$ during second-order training. Recent evidence that might support this view comes from a study of secondary reinforcement (Amorapanth et al. 2000). Lesions of the basal nucleus of the amygdala prevented a fearful CS (i.e., S1) from supporting acquisition of an instrumental escape response but did not disrupt freezing to the

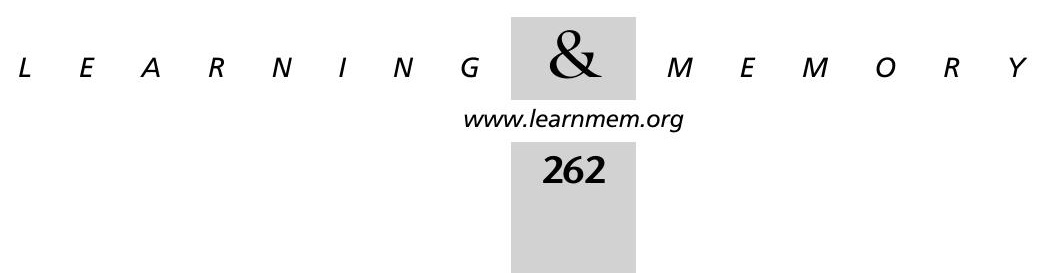


CS itself. In contrast, lesions of the lateral nucleus blocked both conditioned freezing and the ability of the CS to support instrumental learning. This might suggest that the plasticity underlying higher-order learning (in this case, CS-signaled escape learning) occurs in the amygdala downstream of the site of plasticity of first-order conditioning. Alternatively, plasticity underlying higher-order learning may occur in the lateral nucleus, with the basal nucleus forming a conduit for expression of escape behavior.

\section{Mechanisms of Reinforcement II: Other Higher-Order Conditioning Paradigms}

Although the neural substrates of higher-order conditioning are still relatively uncharted, involvement of the BLA is emerging as critical in both Pavlovian second-order conditioning and related learning phenomena. First, the BLA is critically involved in second-order appetitive learning. Excitotoxic lesions of the BLA block acquisition of a secondorder appetitive conditioned response (approach toward a food cup) but not of the same response conditioned to a first-order CS (Hatfield et al. 1996). The sparing of the firstorder response rules out an account in terms of performance deficits and suggests instead that the BLA is involved in the acquisition of second-order appetitive conditioning.

In contrast to lesions of the BLA, lesions of the central nucleus of the amygdala (CeA) block both first- and secondorder conditioned orienting responses but not conditioned approach to the food (Hatfield et al. 1996). Based on these and other data, Hatfield et. al. (1996) suggest the CeA "regulates attentional processing of cues during associative conditioning" (Hatfield et al. 1996, p. 5265), whereas the basolateral nucleus of the amygdala is critically involved in "associative learning processes that give CSs access to the motivational value of their associated USs" (Hatfield et al. 1996, p. 5264).

In addition, BLA lesions block the effect of US devaluation (Hatfield et al. 1996). Similarly, in instrumental conditioning, lesions of the BLA impair the ability of rats to detect a decrease in reward magnitude (the "Crespi" or "negative contrast" effect; Becker et al. 1984; Salinas et al. 1996). Thus, BLA lesions may block acquisition of second-order conditioning by blocking access to a memory of the current motivational value of the reinforcer, stored in the posterior insular cortex. Importantly, because acquisition and expression of first-order appetitive conditioning (in contrast to fear conditioning, see above) are not disrupted by the same lesions, a memory of the original value of the appetitive reinforcer must be stored independent of this amygdalocortical network.

As described earlier, lesions of the basal nucleus of the BLA block the secondary reinforcing effects of a fearful CS on acquisition of an avoidance response but do not block freezing (Amorapanth et al. 2000). A similar involvement of the BLA is indicated in appetitive secondary reinforcement as well. Lesions of the BLA markedly reduced the ability of a CS that had been paired with an estrous female to support instrumental acquisition of a lever response. The animal's tendency to respond to the primary reinforcer (the estrous female) was not impaired (Everitt et al. 1989). Finally, in another paradigm related to higher-order conditioning, local infusion of the NMDA antagonist AP5 into the BLA disrupted acquisition of a taste-potentiated odor aversion but not acquisition of a first-order taste aversion (Hatfield and Gallagher 1995).

In summary, several findings now suggest a critical role for the BLA in a variety of higher-order conditioning situations, both aversive and appetitive.

\section{Combined Analysis of First- and Second-Order Conditioning to More Precisely Measure Learning and Memory}

Although applying a treatment (e.g., drug, lesion) before training or testing is typically used to discriminate effects on learning versus performance, this approach is often still problematic. Some of the problems can be overcome by including tests of higher-order conditioning. For example, consider a treatment, such as a drug infused locally into the amygdala, that blocks expression of first-order conditioning when applied before testing, but not acquisition when applied before training, tested at some later time when the treatment no longer is in effect (Table 2). Does the treat-

Table 2. How Second-Order Conditioning Can Help in More Precisely Determining the Effects of a Treatment on Learning and Memory

\begin{tabular}{lllll}
\hline & $\begin{array}{l}\text { First-order } \\
\text { acquisition }\end{array}$ & $\begin{array}{l}\text { First-order } \\
\text { expression }\end{array}$ & $\begin{array}{c}\text { Second-order } \\
\text { acquisition }\end{array}$ & Inference \\
\hline Scenario 1 & No effect & Effect & $\begin{array}{l}\text { No effect } \\
\text { Effect } \\
\text { No effect } \\
\text { Effect }\end{array}$ & $\begin{array}{l}\text { Treatment has effect on response expression } \\
\text { Treatment has effect on memory retrieval } \\
\text { Treatment has effect on transmission of US signal } \\
\text { Treatment has effect on acquisition of new memory }\end{array}$ \\
\hline
\end{tabular}

The treatment is given either before first-order training (to test for an effect on acquisition of first-order conditioning), before first-order testing (to test for an effect on expression of first-order conditioning), or before second-order training (to test for an effect on acquisition of second-order conditioning).

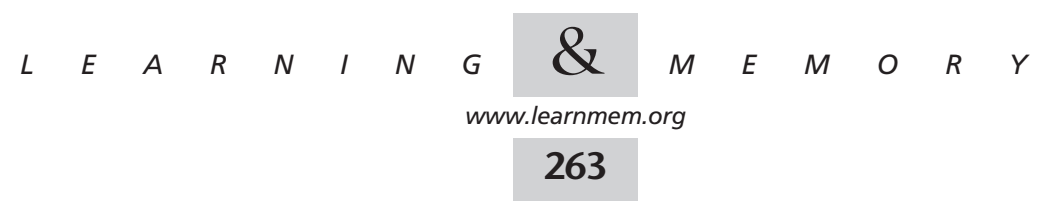


ment act by blocking memory activation or does it act further downstream by blocking elicitation of a behavioral response? To distinguish between these possibilities one can test the ability of the drug to block acquisition of secondorder conditioning. Recall that S2 becomes associated with a central state of anticipation of reinforcement rather than with a specific peripheral response. Therefore, if acquisition of second-order conditioning also were blocked, it would strongly suggest that the treatment interfered with retrieval of the first-order memory and not with performance of an overt behavioral response.

This rationale has recently been applied to exploring effects of dopamine on fear conditioning. Systemic application of the D2 agonist quinpirol blocks acquisition of second-order conditioning (Nader and LeDoux 1999a). Quinpirol does not, however, disrupt acquisition of sensory preconditioning. (The study did not measure the effects of quinpirol on first-order conditioning, but a sparing of sensory preconditioning effectively provides for the same sorts of controls.) This suggests that D2 receptor stimulation does not interfere in a general way with processes involved in synaptic plasticity or transmission of CS information. The inability to acquire second-order conditioning suggests that D2 receptor stimulation (probably in the ventral tegmental area; Nader and LeDoux 1999b) inhibits the retrieval of a central fear state, rather than the performance of a fearrelated behavior (freezing).

Second, consider a situation where a drug enhances acquisition of a first-order association but not its expression (see Table 2). The most intriguing conclusion would be that the drug facilitated processes involved in the cellular plasticity that underlies associative learning. Alternatively, the drug might have acted by enhancing transmission along central US pathways, perhaps not reflected by lower brain stem or spinal cord measures of US activation. However, if the drug also increased the rate of acquisition of secondorder conditioning this could not be interpreted as reflecting alterations in US processing. This is because the drug would only be given before second-order training sessions, in which the US was not presented (i.e., no refresher trials would be included during second-order training). Using this approach, Cicala et al. (1990) found that the opiate antagonist naloxone enhanced second-order conditioning when given before second-order training. This effect could not be attributed to a change in shock sensitivity because no shocks were given after the drug was administered.

We have also used this rationale to further investigate the role of NMDA-type glutamate receptors in the amygdala in acquisition of conditioned fear. Local infusion of an NMDA receptor antagonist into the amygdala at the time of training disrupts first-order fear conditioning (Miserendino et al. 1990; Campeau et al. 1992; Fanselow and Kim 1994), odor-aversion learning (Staubli et al. 1989), appetitive conditioning (Burns et al. 1994; Baldwin et al. 2000), and in- hibitory avoidance learning (Izquierdo et al. 1992; Kim and McGaugh 1992; Liang et al. 1994). Expression of first-order fear conditioning is not disrupted (Miserendino et al. 1990; Campeau et al. 1992; Liang et al. 1994), indicating that transmission of CS information is intact (but see also Maren et al. 1996; Lee and Kim 1998). Furthermore, intra-amygdala AP5 does not affect reactivity to footshock during fear conditioning (Miserendino et al. 1990; Kim and McGaugh 1992; Liang et al. 1994). However, this measure may reflect only a spinally mediated withdrawal reflex. Thus, one cannot rule out with any confidence the possibility that NMDA antagonists interfered with local transmission of US information in the amygdala during first-order conditioning. To test whether blockade of NMDA receptors in the amygdala interferes with associative learning independent of any effect it might have on US processing, we infused AP5 into the amygdala immediately before second-order conditioning (Gewirtz and Davis 1997a). Importantly, not only did AP5 completely block second-order conditioning but the same dose actually enhanced expression of first-order conditioning (Fig. 5). Because first-order fear provides the rein-

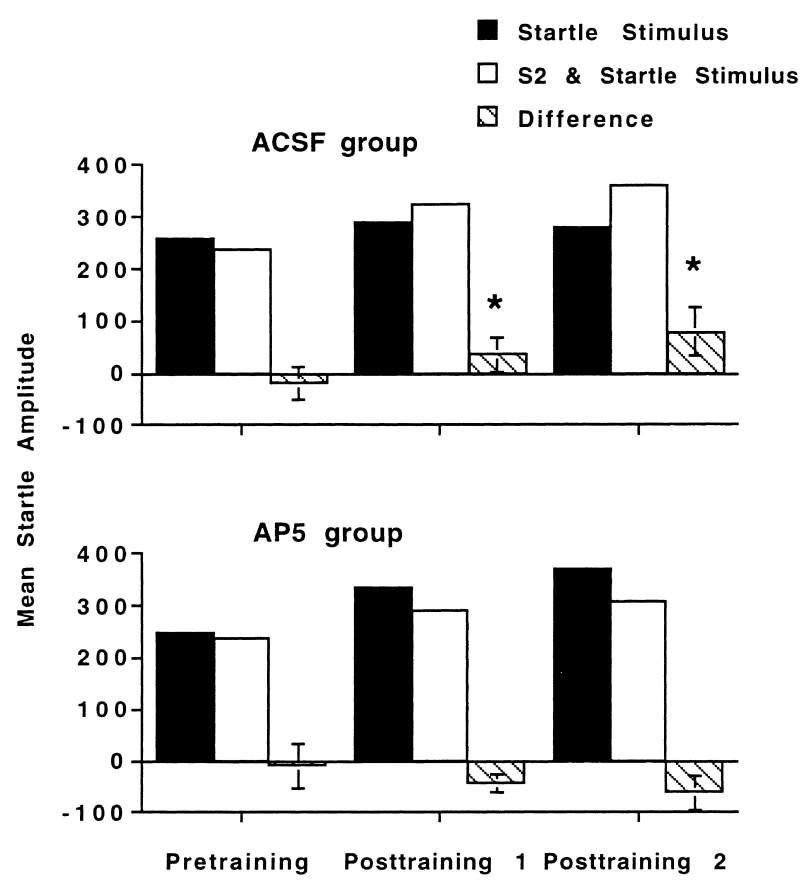

Figure 5 Acquisition of second-order fear-potentiated startle is blocked by microinfusion of the NMDA antagonist AP5 into the BLA. The drug was injected immediately before each session of second-order conditioning. The control group was injected with artificial cerebrospinal fluid (ACSF) vehicle. The three tests were conducted before second-order training (pretraining) and after two (posttraining 1) and three (posttraining 2) sessions of second-order training. No first-order pairings were given during second-order training. Fear-potentiated startle is defined as the difference $( \pm$ SEM) in startle amplitude measured in the presence versus absence of the CS. Figure first published in Gewirtz and Davis (1997a) and reproduced with permission of the publisher.

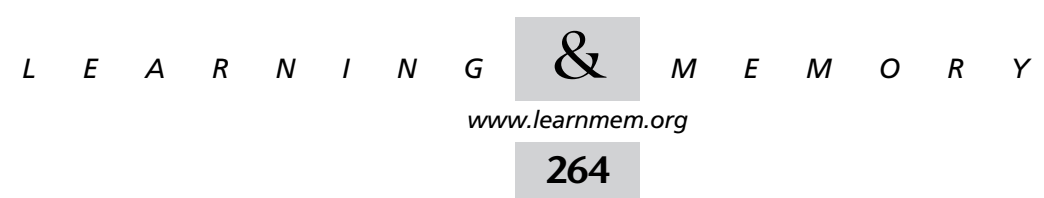


forcement signal for second-order conditioning, this strongly suggests that AP5 did not block second-order conditioning by disrupting transmission of the reinforcement signal to the amygdala.

\section{Conclusion}

The foregoing discussion has illustrated several ways in which higher-order conditioning can be used to analyze neural substrates of learning and memory. The value of higher-order conditioning stems from the fact that the reinforcer has motivational value that is acquired, as opposed to intrinsic motivational value. As a result, higher-order conditioning can be used to investigate the neural substrates of different forms of associative memory and to identify processes involved in learning and memory versus processes involved in transmission of sensory or motor information.

Beyond this, however, the value of higher-order conditioning to the neurobiologist or learning theorist may be greater than its usefulness as a laboratory instrument. It is likely that most sources of reinforcement in ethological settings have acquired motivational significance rather than any particular intrinsic value. This point is easy to overlook. For example, the sight of a banana can clearly serve as a powerful reinforcing stimulus for a monkey, but the monkey first has to learn to associate its appearance with its odor and taste (Gaffan 1992). Similarly, little human learning presumably involves the direct pairing of objects or events with powerful, unconditioned reinforcers. Hence, higher-order conditioning offers a bridge between Pavlovian conditioning experiments conducted inside the laboratory and the types of learning that perhaps predominate in the outside world.

\section{ACKNOWLEDGMENTS}

This work was supported by NIH Grants MH47840, MH57250, MH58922, MH52384, MH59906, MH11370, and the Woodruff Foundation.

\section{REFERENCES}

Amorapanth, P., LeDoux, J.E., and Nader, K. 2000. Different lateral amygdala outputs mediate reactions and actions elicited by a fear-arousing stimulus. Nature Neurosci. 3: 74-79.

Archer, T. and Sjoden, P.-O. 1982. Higher-order conditioning and sensory preconditioning of a taste aversion with an exteroreceptive CS1. Quart. J. Exp. Psychol. 34B: 1-17.

Baldwin, A.E., Holahan, M.R., Sadeghian, K., and Kelley, A.E. 2000. $\mathrm{N}$-methyl-D-aspartate receptor-dependent plasticity within a distributed corticostriatal network mediates appetitive instrumental learning. Behav. Neurosci. 114: 84-98.

Barnet, R.C. and Miller, R.R. 1996. Second-order excitation mediated by a backward conditioned inhibitor. J. Exp. Psychol. Anim. Behav. Process. 22: 279-296.

Becker, H.C., Jarvis, M.F., Wagner, G.C., and Flaherty, C.F. 1984. Medial and lateral amygdalectomy differentially influences consummatory negative contrast. Physiol. Behav. 33: 707-712.

Burns, L.H., Everitt, B.J., and Robbins, T.W. (1994). Intra-amygdala infusion of the N-methyl-D-aspartate receptor antagonist AP5 impairs acquisition but not performance of discriminated approach to an appetitive CS. Behav. Neural Biol. 61: 242-250.

Campeau, S. and Davis, M. 1995a. Involvement of subcortical and cortical afferents to the lateral nucleus of the amygdala in fear conditioning measured with fear-potentiated startle in rats trained concurrently with auditory and visual conditioned stimuli. J. Neurosci. 15: 2312-2327.

- 1995b. Involvement of the central nucleus and basolateral complex of the amygdala in fear conditioning measured with fear-potentiated startle in rats trained concurrently with auditory and visual conditioned stimuli. J. Neurosci. 15: 2301-2311.

Campeau, S., Miserendino, M.J.D., and Davis, M. 1992. Intra-amygdala infusion of N-methyl-D-aspartate receptor antagonist AP5 blocks acquisition but not expression of fear-potentiated startle to an auditory conditioned stimulus. Behav. Neurosci. 106: 569-574.

Cicala, G.A., Azorlosa, J.L., Estall, L.B., and Grant, S.J. 1990. Endogenous opioids interfere with Pavlovian second-order fear conditioning. Psychol. Sci. 1: 312-314.

Corodimas, K.P. and LeDoux, J.E. 1995. Disruptive effects of posttraining perirhinal cortex lesions on conditioned fear: Contributions of contextual cues. Behav. Neurosci. 109: 613-619.

Davis, M., Schlesinger, L.S., and Sorenson, C.A. 1989. Temporal specificity of fear conditioning: Effects of different conditioned stimulusunconditioned stimulus intervals on the fear-potentiated startle effect. J. Exp. Psychol. Anim. Behav. Process. 15: 295-310.

Everitt, B.J., Cador, M., and Robbins, T.W. 1989. Interactions between the amygdala and ventral striatum in stimulus-reward associations: Studies using a second-order schedule of reinforcement. Neuroscience 30: $63-75$

Falls, W.A., Bakker, K.T., and Heldt, S.A. 1997. Lesions of perirhinal cortex interfere with conditioned excitation but not with conditioned inhibition of fear. Behav. Neurosci. 111: 476-486.

Falls, W.A. and Davis, M. 1997. Inhibition of fear-potentiated startle can be detected after the offset of a feature trained in a serial feature-negative discrimination. J. Exp. Psychol. Anim. Behav. Process. 23: 3-14.

Fanselow, M.S. and Kim, J.J. 1994. Acquisition of contextual Pavlovian fear conditioning is blocked by application of an NMDA receptor antagonist D,L-2-Amino-5-Phosphonovaleric acid to the basolateral amygdala. Behav. Neurosci. 108: 210-212.

Gaffan, D. 1992. Amygdala and the memory of reward. In The amygdala: Neurobiological aspects of emotion, memory, and mental dysfunction (ed. J.P. Aggleton). Wiley-Liss, New York.

Gewirtz, J.C. 1998. Second-order conditioning of fear-potentiated startle. Unpublished Ph.D. thesis, Yale University.

Gewirtz, J.C. and Davis, M. 1997a. Second-order fear conditioning prevented by blocking NMDA receptors in amygdala. Nature 388: $471-474$.

-1997b. Application of Pavlovian higher-order conditioning to the analysis of the neural substrates of fear conditioning. Neuropharmacology 37: 453-459.

Hatfield, T. and Gallagher, M. 1995. Taste-potentiated odor conditioning: Impairment produced by infusion of an N-Methyl-D-Aspartate antagonist into basolateral amygdala. Behav. Neurosci. 109: 663-668.

Hatfield, T., Han, J.-S., Conley, M., Gallagher, M., and Holland, P. 1996. Neurotoxic lesions of basolateral, but not central, amygdala interfere with Pavlovian second-order conditioning and reinforcer devaluation effects. J. Neurosci. 16: 5256-5265.

Helmstetter, F.J. and Fanselow, M.S. 1989. Differential second-order aversive conditioning using contextual stimuli. Anim. Learn. Behav. 17: 205-212.

Herendeen, D. and Anderson, D.C. 1968. Dual effects of a second-order conditioned stimulus: Excitation and inhibition. Psychon. Sci. 13: $15-16$

Holland, P.C. 1977. Conditioned stimulus as a determinant of the form of the Pavlovian conditioned response. J. Exp. Psychol. Anim. Behav. Process. 3: 77-104.

Holland, P.C. and Rescorla, R.A. 1975a. The effect of two ways of devaluing the unconditioned stimulus after first- and second-order appetitive conditioning. J. Exp. Psychol. Anim. Behav. Process. 1: 355-363.

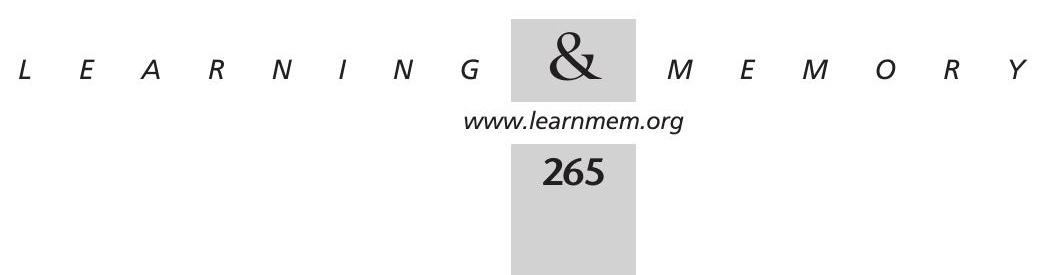


- 1975b. Second-order conditioning with food unconditioned stimulus. J. Comp. Physiol. Psychol. 88: 459-467.

Hull, C.L. 1943. Principles of behavior. Appleton-Century-Crofts, New York.

Izquierdo, I., Da Cunha, C., Rosat, R., Jerusalinsky, D., Ferreira, M.B.C., and Medina, J.H. (1992). Neurotransmitter receptors involved in memory processing by the amygdala, medial septum and hippocampus of rats. Behav. Neural Biol. 60: 16-26.

Kamil, A.C. 1969. Some parameters of the second-order conditioning of fear in rats. J. Comp. Physiol. Psychol. 67: 363-369.

Kehoe, E.J., Feyer, A.-M., and Moses, J.L. 1981. Second-order conditioning of the rabbit's nictitating membrane response as a function of the CS2-CS1 and CS1-US intervals. Anim. Learn. Behav. 9: 304-315.

Kim, M. and McGaugh, J.L. 1992. Effects of intra-amygdala injections of NMDA receptor antagonists on acquisition and retention of inhibitory avoidance. Brain Res. 585: 35-48.

Kim, M., Campeau, S., Falls, W.A., and Davis, M. 1993. Infusion of the non-NMDA receptor antagonist CNQX into the amygdala blocks expression of fear-potentiated startle. Behav. Neural Biol. 59: 5-8.

Kim, S.D., Rivers, S., Bevins, R.A., and Ayres, J.J.B. 1996. Conditioned stimulus determinants of conditioned response form in Pavlovian fear conditioning. J. Exp. Psychol. Anim. Behav. Process. 22: 87-104.

Konorski, J. 1948. Conditioned reflexes and neuron organization. Hafner, New York.

Konorski, J. 1967. Integrative activity of the brain. University of Chicago Press, Chicago.

Lee, H. and Kim, J.J. 1998. Amygdalar NMDA receptors are critical for new fear learning in previously fear-conditioned rats. J. Neurosci. 18: 8444-8454.

Leyland, C.M. 1977. Higher order autoshaping. Quart. J. Exp. Psychol. 29: 607-619.

Liang, K.C., Hon, W., and Davis, M. 1994. Pre- and posttraining infusion of N-Methyl-D-Aspartate receptor antagonists into the amygdala impair memory in an inhibitory avoidance task. Behav. Neurosci. 108: $241-253$

Maren, S., Aharonov, G., Stote, D.L., and Fanselow, M.S. 1996 N-Methyl-D-Aspartate receptors in the basolateral amygdala are required for both acquisition and expression of conditioned fear in rats. Behav. Neurosci. 110: 1365-1374.

McAllister, D.E. and McAllister, W.R. 1964. Second-order conditioning of fear. Psychon. Sci. 1: 383-384.

Miller, N.E. 1951. Comments on multiple-process conceptions of learning. Psychol. Rev. 58: 375-381.

Miserendino, M.J.D., Sananes, C.B., Melia, K.R., and Davis, M. 1990. Blocking of acquisition but not expression of conditioned fear-potentiated startle by NMDA antagonists in the amygdala. Nature 345: $716-718$

Mowrer, O.H. 1960. Learning theory and symbolic processes. Wiley, New York.

Nader, K. and LeDoux, J.E. 1999a. The dopaminergic modulation of fear: Quinpirole impairs the recall of emotional memories in rats. Behav. Neurosci. 113: 152-165.

- 1999b. Inhibition of the mesoamygdala dopaminergic pathway impairs the retrieval of conditioned fear associations. Behav. Neurosci. 113: 891-901.

Pavlov, I.P. 1927. Conditioned reflexes: An investigation of the physiological activity of the cerebral cortex (G.V. Anrep, trans.). Dover, New York.

Pfautz, P.L., Donegan, N.H., and Wagner, A.R. 1978. Sensory preconditioning versus protection from habituation. J. Exp. Psychol. Anim. Behav. Process. 4: 286-295.

Pitkänen, A., Stefanacci, L., Farb, C.R., Go, G.G., LeDoux, J.E., and Amaral, D.G. 1995. Intrinsic connections of the rat amygdaloid complex: Projections originating in the lateral nucleus. J. Comp. Neurol. 356: 288-310

Prewitt, E.P. 1967. Number of preconditioning trials in sensory preconditioning using CER training. J. Comp. Physiol. Psychol. 64: $360-362$

Rashotte, M.E. 1981. Second-order conditioning: Contributions to the research and theory of Pavlovian reinforcement by conditioned stimuli. In Autoshaping and conditioning theory (eds. C.M. Locurto, H.S. Terrace, and J. Gibbon). Academic Press, New York.

Rashotte, M.E., Griffin, R.W., and Sisk, C.L. 1977. Second-order conditioning of the pigeon's keypeck. Anim. Learn. Behav. 5: 25-38.

Rescorla, R.A. 1973. Second-order conditioning: Implications for theories of learning. In Contemporary approaches to conditioning and learning (eds. F.J. McGuigan and D.B. Lumsden), pp. 127-150. V.H. Winston, Washington DC.

- 1979. Aspects of the reinforcer learned in second-order Pavlovian conditioning. J. Exp. Psychol. Anim. Behav. Process. 5: 79-95.

. 1980a. Pavlovian second-order conditioning: Studies in associative learning. Erlbaum, NJ.

-1980b. Simultaneous and successive associations in sensory preconditioning. J. Exp. Psychol. Anim. Behav. Process. 6: 207-216. - 1982. Simultaneous second-order conditioning produces S-S learning in conditioned suppression. J. Exp. Psychol. Anim. Behav. Process. 8: 23-32.

-1999. Partial reinforcement reduces the associative change produced by nonreinforcement. J. Exp. Psychol. Anim. Behav. Process. 25: 403-414.

Rescorla, R.A. and Cunningham, C.L. 1979. Spatial contiguity facilitates Pavlovian second-order conditioning. J. Exp. Psychol. Anim. Behav. Process. 5: 152-161.

Rescorla, R.A. and Durlach, P.J. 1981. Within-event learning in Pavlovian conditioning. In Information processing in animals: Memory mechanisms (eds. N.E. Spear and R.R. Miller). Erlbaum, NJ.

Rescorla, R.A., and Furrow, D.R. 1977. Stimulus similarity as a determinant of Pavlovian conditioning. J. Exp. Psychol. Anim. Behav. Process. 3: 203-215.

Rizley, R.C. and Rescorla, R.A. 1972. Associations in second-order conditioning and sensory preconditioning. J. Comp. Physiol. Psychol. 81: $1-11$.

Robinson, T.E. and Berridge, K.C. 1993. The neural basis of drug craving: An incentive-sensitization theory of addiction. Brain Res. Rev. 18: $247-291$.

Romanski, L.M. and LeDoux, J.E. 1992. Bilateral destruction of neocortical and perirhinal projection targets of the acoustic thalamus does not disrupt auditory fear conditioning. Neurosci. Lett. 142: 228-232.

Romanski, L.M., Clugnet, M.-C., Bordi, F., and LeDoux, J.E. 1993. Somatosensory and auditory convergence in the lateral nucleus of the amygdala. Behav. Neurosci. 107: 444-450.

Rosen, J.B., Hitchcock, J.M., Miserendino, M.J.D., Falls, W.A., Campeau, S., and Davis, M. 1992. Lesions of the perirhinal cortex but not of the frontal, medial, prefrontal, visual, or insular cortex block fear-potentiated startle using a visual conditioned stimulus. J. Neurosci. 12: 4624-4633.

Ross, R.T. 1986. Pavlovian second-order conditioned analgesia. J. Exp. Psychol. Anim. Behav. Process. 12: 32-39.

Rozeboom, W.W. 1958. "What is learned?"-An empirical enigma. Psychol. Rev. 65: 22-33.

Salinas, J.A., Parent, M.B., and McGaugh, J.L. 1996. Ibotenic acid lesions of the amygdala basolateral complex or central nucleus differentially effect the response to reductions in reward. Brain Res. 742: 283-293.

Shi, C. 1995. The anatomical substrates underlying the role of the amygdala in associative learning. Unpublished Ph.D. thesis, University of Iowa.

Stanhope, K.J. 1992. The representation of the reinforcer and the force of the pigeon's keypeck in first- and second-order conditioning. Quart. J. Exp. Psychol. 44: 137-158.

Staubli, U., Thibault, O., DiLorenzo, M., and Lynch, G. 1989. Antagonism of NMDA receptors impairs acquisition but not retention of olfactory memory. Behav. Neurosci. 103: 54-60.

Tait, R.W., Marquis, H.A., Williams, R., Weinstein, L., and Suboski, M.D 1969. Extinction of sensory preconditioning using CER training. $J$. Comp. Physiol. Psychol. 69: 170-172.

Yin, H., Barnet, R.C., and Miller, R.R. 1994. Second-order conditioning and Pavlovian conditioned inhibition: Operational similarities and differences. J. Exp. Psychol. Anim. Behav. Process. 20: 419-428.

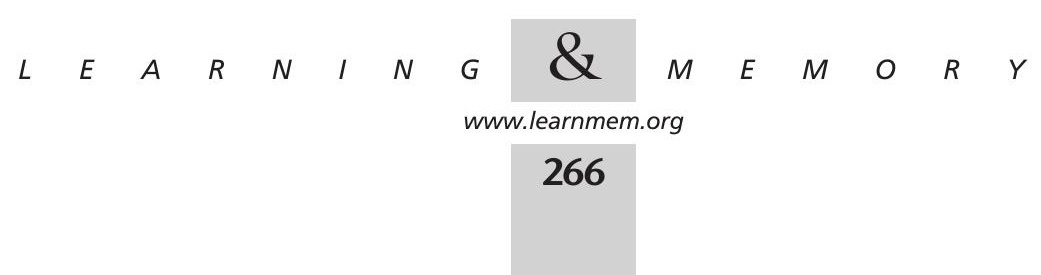




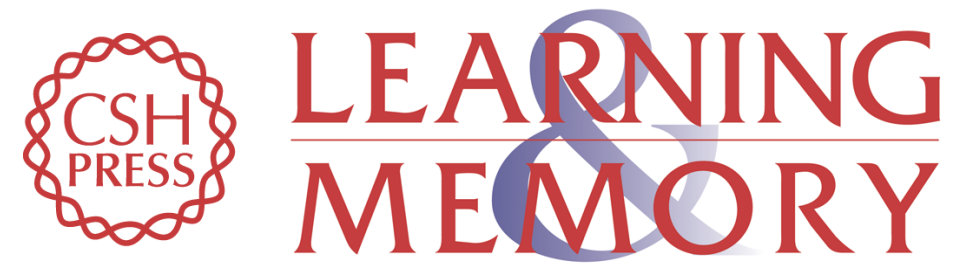

\section{Using Pavlovian Higher-Order Conditioning Paradigms to Investigate the Neural Substrates of Emotional Learning and Memory}

Jonathan C. Gewirtz and Michael Davis

Learn. Mem. 2000, 7:

Access the most recent version at doi: $10.1101 / \mathrm{lm} .35200$

References This article cites 58 articles, 5 of which can be accessed free at: http://learnmem.cshlp.org/content/7/5/257.full.html\#ref-list-1

License

Email Alerting

Receive free email alerts when new articles cite this article - sign up in the box at the Service top right corner of the article or click here. 